\title{
Toxicity of fluorescent tracers and their degradation byproducts
}

\author{
Philippe Gombert ${ }^{1 *}$, Hugues Biaudet ${ }^{1}$, René de Seze ${ }^{1}$, Pascal Pandard ${ }^{1}$, and Jean Carré2 \\ ${ }^{1}$ INERIS, Parc Technologique Alata BP2, 60550 Verneuil-en-Halatte, France \\ ${ }^{2}$ EHESP, Département Santé-Environnement travail, avenue du Pr. Léon Bernard, 35043 Rennes cedex, France
}

\begin{abstract}
Tracer tests are frequently used to delineate catchment area of water supply springs in karstic zones. In the karstic chalk of Normandy, the main tracers used are fluorescent: uranine, sulforhodamine $B$, naphtionate, and Tinopal $($. In this area, a statistical analysis shows that less than half of the injected tracers joins the monitored restitution points and enters the drinking water system where they undergo chlorination. Most of the injected tracers is absorbed in the rock matrix or is thrown out of the aquifer via karstic springs: then it can join superficial waters where it is degraded due to the sun and air action. The paper presents firstly the laboratory degradation of a first batch of fluorescent tracers in contact with chlorine, in order to simulate their passage through a water treatment system for human consumption. A second batch of the same tracers is subjected to agents of natural degradation: ultraviolet illumination, sunlight and air sparging. Most tracers is degraded, and toxicity and ecotoxicity tests (on rats, daphniae and algae) are performed on degradation byproducts. These tests do not show any acute toxicity but a low to moderate ecotoxicity. In conclusion, the most used fluorescent tracers of the Normandy karstic chalk and their artificial and natural degradation byproducts do not exhibit significant toxicity to humans and the aquatic environment, at the concentrations generally noted at the restitution points.
\end{abstract}

Keywords: $\quad$ tracer, degradation, toxicity, ecotoxicity, chalk

Received 2 May 2016; Revised 2 January 2017; Accepted 3 January 2017

Citation: Gombert P., Biaudet H., de Seze R., Pandard P. and Carré J., 2017. Toxicity of fluorescent tracers and their degradation byproducts. International Journal of Speleology, 46 (1), 23-31. Tampa, FL (USA) ISSN 0392-6672 https://doi.org/10.5038/1827-806X.46.1.1995

\section{INTRODUCTION}

The positive tracer tests can involve a monitored drinking water extraction point. In this case, the injected tracer undergoes the same treatment as the water before entering the distribution system and reaching the tap of the consumer (Gombert, 2007; Goldscheider et al., 2008). Submitted to the action of drinking water treatment agents, which are mostly strong oxidizers (chlorine, bleach, chlorine dioxide, ozone, bromine, and UV radiations), the fluorescent tracer can degrade to byproducts.

However, the fate of the injected tracer is unknown in the case of negative tracer tests. It may remain adsorbed underground (generally due to clay or rich organic sediments) or seep out of the aquifer through nonmonitored karstic springs, and then join surface waters where it may be degraded by sunlight and/or air action.

This paper examines the potential (eco)toxicological impacts of such tracer degraded by-products of which we know neither the nature nor the toxicity to humans

Even if the possible evolution of degradation and transformation products has been partly assessed, the previous studies regarding tracers' (eco)toxicity have not taken into account the effects of such byproducts (Field et al., 1995; Behrens et al., 2001; Meus et al., 2014). In the present work, an attempt was made to estimate the possible adverse effects on human health and the environment caused by water containing a fluorescent tracer and its degradation byproduct(s).

For this purpose, laboratory experiments were carried out consisting of solutions of the main fluorescent tracers in their degraded state under two different conditions: (i) contact with gaseous chlorine to simulate passage of the tracer through the water treatment system used for producing drinking water, and (ii) UV and artificial sunlight illumination with air sparging to represent the natural degradation conditions. The solutions obtained were analyzed and their acute toxicity (acute toxicity to rats) and ecotoxicity (mobility of daphnids and growth of microalgae) were measured.

\section{NATURE AND DOSE OF SELECTED TRACERS}

\section{Area presentation}

The nature and the dose of tracers used in this work come from previous statistical studies of tracer tests realized in the western part of the Paris Basin, 
called Normandy (Gombert, 2007, 2008). This is a $10,000 \mathrm{~km}^{2}$ chalky area that contains nearly 500 groundwater wells and karstic springs used for water supply (Fig. 1). The previous studies showed that $47 \%$ of the injected tracers reach a drinking water extraction point, and $53 \%$ of them are lost.

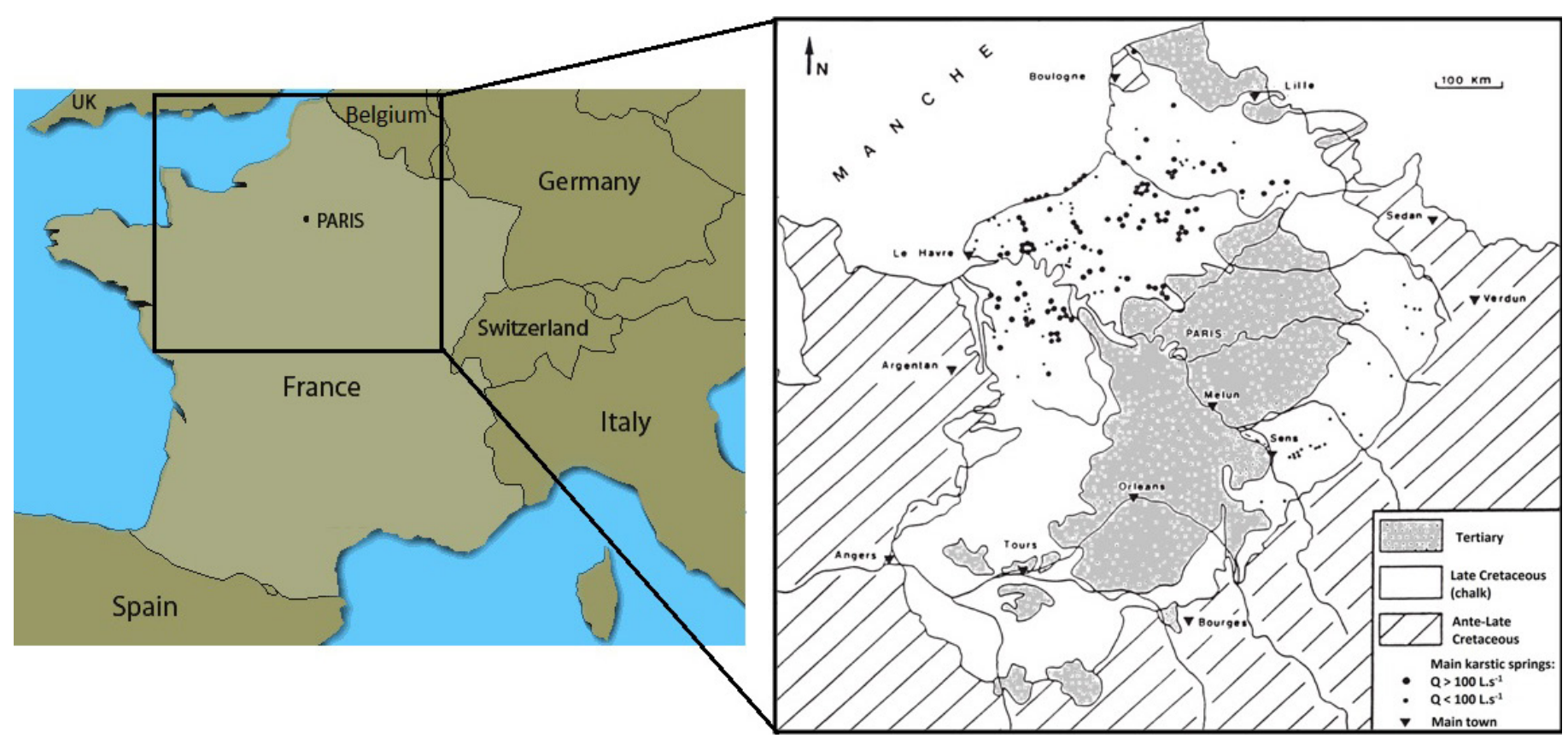

Fig. 1. Location of Normandy in the Paris basin (according to Crampon et al., 1993).

\section{Nature of tracers}

In the context of limestone (Käss, 1998) as well as in the context of Normandy chalk (Gombert, 2007), fluorescent and ionic tracers are the most common tracers. The fluorescent tracers are mainly used because of their moderate cost, their low detection level and their easy detection method (Goldscheider et al., 2008). The main fluorescent tracers are uranine, sodium naphtionate, sulforhodamines, stilbenes such as Tinopal ${ }^{\circledR}$, eosin, rhodamines, etc. They are molecules with long carbon chains or aromatic cycles with 10 to 30 carbon atoms. This molecular structure produces the fluorescent phenomena but also some predisposition to adsorption and the degradation process.

We selected the four main fluorescent tracers used in the karstic chalk of Normandy (Gombert, 2008): uranine $\left(\mathrm{C}_{20} \mathrm{H}_{10} \mathrm{O}_{5} \mathrm{Na}_{2}\right)$, sulforhodamine $\mathrm{B}$ $\left(\mathrm{C}_{27} \mathrm{H}_{30} \mathrm{~N}_{2} \mathrm{O}_{7} \mathrm{~S}_{2} \cdot \mathrm{Na}\right)$, sodium naphtionate $\left(\mathrm{C}_{10} \mathrm{H}_{8} \mathrm{NSO}_{3} \mathrm{Na}\right)$, and Tinopal ${ }^{\circledR}$ CBS-X $\left(\mathrm{C}_{28} \mathrm{H}_{22} \mathrm{~S}_{6} \mathrm{O}_{2} \mathrm{Na}_{2}\right)$. The first two have an intense, distinctive color (green and red, respectively), but the last two are colorless tracers, detectable only by ultraviolet excitation.

\section{Dose of tracers}

Most tracers are available in powder form and must be diluted in water prior to injection. The required dose is generally calculated by empirical formulas (Field, 2003) mainly dependent on the nature of the tracer, the distance to trace, the flow of the breakthrough point and/or the concentration expected at this point. The most commonly used dose is approximately $1 \mathrm{~kg}$ of tracer per $1 \mathrm{~km}$ of distance to trace (Gombert, 2007, 2008). This dose is mainly valid for uranine, and several authors have proposed a correction factor for other tracers: 1 (Gombert, 2008) to 4 (Käss, 1998; Benischke et al., 2007) for sulforhodamine B,
2 for Tinopal® (Gombert, 2008), 2.4 (Gombert, 2008) to 15 (Käss, 1998; Benischke et al., 2007) for naphthionate. However, in the context of the karstic chalk of Normandy, the analysis of 87 tracer injection data provides a $1.4 \mathrm{~kg} \cdot \mathrm{km}^{-1}$ average uranine dose: this corresponds to an average 1.4 correction factor, close to the most commonly used empirical dose. This also indicates that the injection solution must be highly concentrated, usually several hundred $\mathrm{g} \cdot \mathrm{L}^{-1}$.

At the other end of the tracing system, Gombert $\&$ Carré (2011) have examined 210 recoveries of fluorescent tracer tests in the same karstic context: the average concentration calculated at the breakthrough peak is $19 \mu \mathrm{g} \cdot \mathrm{L}^{-1}$ and the maximum concentration exceeds $500 \mu \mathrm{g} \cdot \mathrm{L}^{-1}$ in $3 \%$ of cases with a maximum of $800 \mu \mathrm{g} \cdot \mathrm{L}^{-1}$.

As a result of these findings, the tracer solutions tested in our experiments were prepared at an intermediate value between the concentrations of the injection point $\left(>100 \mathrm{~g} \cdot \mathrm{L}^{-1}\right)$ and the breakthrough point $\left(<1 \mathrm{mg} \cdot \mathrm{L}^{-1}\right)$. We chose a representative - and reasonable majorant - value of $1 \mathrm{~g} \cdot \mathrm{L}^{-1}$ to provide an idea of the average tracer concentration that must circulate in this chalky karstic aquifer.

\section{STATE OF THE ART OF THE (ECO)TOXICITY OF FLUORESCENT TRACERS}

\section{Toxicity studies}

The effects of fluorescent tracers on human health have received little attention (Carré et al., 2007) and no acute toxicity problems related to the use of these products have been reported in any studies. International toxicological databases contain no information on these molecules, and the International Agency for Research on Cancer (IARC) website contains information only for rhodamine $B$, rhodamine $6 \mathrm{G}$ 
and eosin. Similarly, there is no literature on doseresponse relationships, at least for oral exposure. In the absence of toxicological reference values and therefore the possibility to quantify the risk, two approaches were developed to decide on the latter and to define the conditions for utilization of the products.

The first approach concerns the toxicity of 12 dyes evaluated by the EPA under a method developed to assess the toxicity of industrial products (Smart, 1984). The risk level is low for uranine, low to medium for sulforhodamine B (and rhodamines B, Wt and G) and for the bleaching agent 28 (Tinopal ${ }^{\circledR}$ family), and average for the bleaching agents 22 and 351 (Tinopal ${ }^{\circledR}$ family). Moreover, several authors, including Field et al. (1995) and Carré et al. (2007), demonstrated that none of the fluorescent tracers may induce significant health effects if their concentration is maintained below $1-2 \mathrm{mg} \cdot \mathrm{L}^{-1}$ during $24 \mathrm{~h}$. The second approach was applied by a working group, initiated by the German Federal Environment Agency, which focused on the genotoxicity of 11 tracer dyes (Behrens et al., 2001). A genotoxic effect was observed only for rhodamine B, rhodamine 6G and naphtionate. No information is available for sulforhodamine $\mathrm{B}$. The group recommended using uranine, naphthionate and Tinopal ${ }^{\circledR}$ (CBS-X and ABP) without limitations, but the use of rhodamines $\mathrm{Wt}, \mathrm{B}$, and $6 \mathrm{G}$ was not advised.

\section{Ecotoxicity studies}

Data regarding the ecotoxicological properties of fluorescent tracers are scarce. Molinari \& Rochat (1978) have described a relatively low ecotoxicological risk for Rhodamine $\mathrm{Wt}$, uranine and Photine, and a more important one - but not quantified - for
Rhodamine B and Sulforhodamine B. In Behrens et al. (2001), ecotoxicological assessments were based on the determination of acute toxicity to daphnids and to zebrafish. Uranine, eosin yellow, amidorhodamine $\mathrm{G}$, sodium naphthionate, pyranine and Tinopal ${ }^{\circledR}$ (CBS-X and ABP liquid) showed no effects. Conversely, significant inhibitory effects were observed for sulforhodamine B on the mobility of Daphnia magna: the 0\% Effect Concentration $\left(\mathrm{EC}_{0}\right)$ for $48 \mathrm{~h}$ is $0.7 \mathrm{mg} \cdot \mathrm{L}^{-1}$ and the $50 \%$ Effect Concentration $\left(\mathrm{EC}_{50}\right)$ for $48 \mathrm{~h}$ is $0.16 \mathrm{mg} \cdot \mathrm{L}^{-1}$. Regarding primary producers, due to interferences caused by the fluorescence of some of the tracers, the authors concluded that the algae test provided no conclusive results and therefore could not be used for ecotoxicological assessments.

Rowinski \& Chrzanowski (2011) studied the acute toxicity of rhodamine B and rhodamine WT using larvae of the microcrustacean Thamnocephalus platyurus. Their results showed a higher toxicity of rhodamine $\mathrm{B}$ compared with rhodamine WT $\left(\mathrm{EC}_{50}\right.$ $24 \mathrm{~h}: 8.1 \mathrm{mg} \cdot \mathrm{L}^{-1} ; \mathrm{EC}_{50} 24 \mathrm{~h}: 1698 \mathrm{mg} \cdot \mathrm{L}^{-1}$, respectively).

In addition to the data presented above, the environmental database (European Chemical Agency (ECHA)/Registered Substance Database, U.S. Environmental Protection Agency (USEPA)/Ecotox Database) and material safety datasheets (MSDS) submitted by the suppliers of fluorescent tracers gather some EC50 and No Observed Effect Concentration (NOEC) values regarding microcrustaceans and algae (Table 1). Generally speaking, these results showed a low toxicity of the selected tracers towards daphnids compared with algae. According to these data, the algal growth inhibition test seems a more appropriate tool to assess ecotoxicity of these compounds.

Table 1. Ecotoxicity data available in Ecotoxicity database and MSDS. D. pulex: Daphnia pulex; D. magna: Daphnia magna; C. dubia: Ceriodaphnia dubia; D. subspicatus: Desmodesmus subspicatus; LCX: Lethal Concentration for X\% of affected individuals; n.a.d.: no available data; ${ }^{*}$ data from Material Safety Data Sheets (MSDS).

\begin{tabular}{|c|c|c|c|}
\hline Tracer & Microcrustacean immobilization test & Algal growth inhibition test & Toxicity on fish \\
\hline Uranine & $\begin{array}{c}\mathrm{EC}_{50} 48 \mathrm{~h}: 337 \mathrm{mg} \cdot \mathrm{L}^{-1} \text { (D. pulex) (USEPA, } \\
\text { 2015; Walthall \& Stark, 1999) }\end{array}$ & $\begin{array}{l}\text { n.a.d. due to interferences caused } \\
\text { by the fluorescence of tracers }\end{array}$ & $\begin{array}{l}\mathrm{LC}_{50} 48 \mathrm{~h}^{*}: 10 \text { to } 100 \\
\mathrm{mg} \cdot \mathrm{L}^{1} \text { (Rainbow trout) }\end{array}$ \\
\hline Sulforho-damine B & $\begin{array}{l}\mathrm{EC}_{0} 48 \mathrm{~h}: 0.16 \mathrm{mg} \cdot \mathrm{L}^{-1} \text { (Behrens et al., 2001) } \\
\mathrm{EC}_{50} 48 \mathrm{~h}: 0.7 \mathrm{mg} \cdot \mathrm{L}^{1} \text { (Behrens et al., 2001) }\end{array}$ & $\begin{array}{l}\text { n.a.d. due to interferences caused } \\
\text { by the fluorescence of tracers }\end{array}$ & $\begin{array}{l}\mathrm{LC}_{50} 48 \mathrm{~h}^{*}: 100 \text { to } 500 \\
\mathrm{mg} \cdot \mathrm{L}^{1} \text { (Rainbow trout) }\end{array}$ \\
\hline $\begin{array}{l}\text { Sodium } \\
\text { naphtionate }\end{array}$ & $\begin{array}{c}\mathrm{EC}_{50} 48 \mathrm{~h} \text { : } 2791 \mathrm{mg} \cdot \mathrm{L}^{-1} \text { (D. magna) Predicted } \\
\text { data QSAR toolbox (ECHA, 2015) }\end{array}$ & $\begin{array}{c}\mathrm{EC}_{50} 72 \mathrm{~h}: 63.2 \mathrm{mg} \cdot \mathrm{L}^{-1} \\
\text { (P. subcapitata) Predicted data } \\
\text { QSAR toolbox (ECHA, 2015) }\end{array}$ & n.a.d. \\
\hline Tinopal® & $\begin{array}{c}\mathrm{EC}_{50} 24 \mathrm{~h}^{*}:>1000 \mathrm{mg} \cdot \mathrm{L}^{-1} \text { (D. magna) } \\
\text { (ECHA, 2015) } \\
\mathrm{EC}_{50} 48 \mathrm{~h}: 40.3 \mathrm{mg} \cdot \mathrm{L}^{-1} \text { (C. dubia) } \\
\text { (USEPA, 2015) }\end{array}$ & $\begin{array}{l}\text { NOEC } 72 \mathrm{~h}: 3.13 \mathrm{mg} \cdot \mathrm{L}^{-1} \\
\text { (D. subspicatus) (ECHA, 2015) } \\
\mathrm{EC}_{50} 72 \mathrm{~h} \text { : } 10.3 \mathrm{mg} \cdot \mathrm{L}^{-1} \\
\text { (D. subspicatus) (ECHA, 2015) }\end{array}$ & $\begin{array}{rl}\mathrm{LC}_{50} & 96 \mathrm{~h} *: 76 \mathrm{mg} \cdot \mathrm{L}^{-1} \\
& \text { (Zebra fish) }\end{array}$ \\
\hline
\end{tabular}

\section{MATERIALS AND METHODS OF NEW DEGRADATION EXPERIMENTS}

\section{Tracer degradation protocols}

Two different degradation protocols have been used to simulate the two main degradation conditions of fluorescent tracers: (i) a strong and rapid degradation due to contact with artificial oxidizing agents, such as chlorine, during transit through the water treatment system used for drinking water production, and (ii) a low degradation due to contact with the natural oxidizing agents sunlight and air, during the outflow of traced groundwater out of the karst.
To simulate rapid degradation due to strong oxidizing agents, a volume of $1 \mathrm{~L}$ of each tracer solution at a concentration of $1 \mathrm{~g} \cdot \mathrm{L}^{-1}$ was submitted for 20 minutes to sparging with chlorine gas at a temperature of $20^{\circ} \mathrm{C}$ (Fig. 2A). This chlorine was produced by a chemical reaction due to the introduction of $100 \mathrm{~mL}$ of $50 \%$ sulfuric acid in $600 \mathrm{~mL}$ of bleach containing 2.6\% active chlorine. At the end of the sparging, the mixture of tracer and chlorine solution was left in contact for half an hour to simulate contact between water and chlorine in drinking water treatment basins.

To simulate low degradation due to the gentle natural agents sunlight and air, a volume of $2.5 \mathrm{~L}$ of 
each tracer solution at a concentration of $1 \mathrm{~g} \cdot \mathrm{L}^{-1}$ was poured into a flat $50 \times 35-\mathrm{cm}$ box, forming a $3-\mathrm{cm}$ thick film, and subjected for 24 hours to the following conditions (Fig. 2B): (i) aeration by continuous agitation using 4 magnets turning at low speed and (ii) a simulated 20,000 lux illumination with a 4,000-K white luminotherapy sunlight lamp and a 400-W UV lamp. Note that, for comparison, at its zenith the summer sun emits a 5,800-K light with an average intensity of 50,000 lux, and that we need to add a UV lamp because the luminotherapy lamp used here has a UV filter.

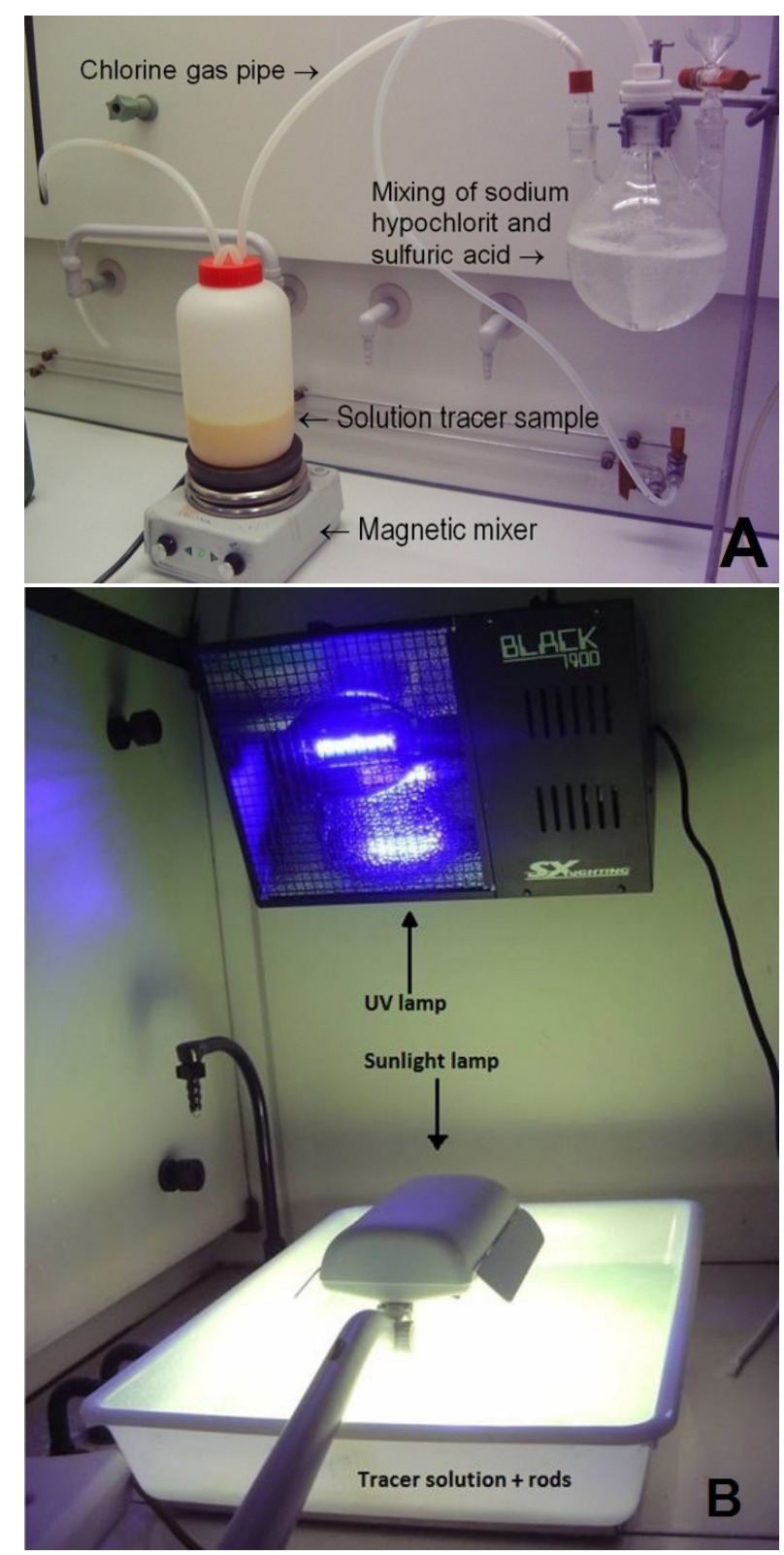

Fig. 2. Experimental setup of tracer degradation (P. Gombert). A) Degradation of uranine by chlorine; B) Degradation of naphtionate by artificial sunlight.

\section{Analytical methods}

The tracer solutions, before and after degradation, were analyzed by a high-performance liquid chromatography (HPLC) instrument, the DIONEX U3000. The injected sample volume was $20 \mu \mathrm{L}$. The separation of compounds was carried out with a C8 column, $250 \mathrm{~mm}$ in length and with a particle size of $5 \mu \mathrm{m}$, with an elution gradient and at a rate of 0.6 to $1 \mathrm{~mL} \cdot \mathrm{min}^{-1}$. The eluent phase was composed of water and acetonitrile. Compounds were detected using two sensors connected in series: a fluorimeter and a diode-array.

The use of a diode-array detector helped to identify the wavelength of maximum absorption for the detection of compounds by plotting the UV spectrum of the molecule. Fluorescence detection, more sensitive than the UV method, was used at the following wavelengths (excitation/emission): 455/ $510 \mathrm{~nm}$ for uranine, $561 / 581 \mathrm{~nm}$ for sulforhodamine $\mathrm{B}, 420 / 454 \mathrm{~nm}$ for naphtionate and 340/429 $\mathrm{nm}$ for Tinopal®. Thus, only compounds with a chemical formula or with excitation and emission properties similar to those of the tracers could be detected at these wavelengths.

The degradation products that appeared were then isolated in the eluate from the liquid chromatography column and analyzed by mass spectrometry (LC-MS) according to both ionization modes (positive ElectroSpray Ionization ESI+ or negative Electro-Spray Ionization ESI-), to isolate their mass spectrum in order to identify the molecules.

\section{Toxicity tests}

The toxicity of tracers without degradation is known from the literature and has been compiled by Gombert $\&$ Carré (2011). We then studied the acute toxicity of the degradation products of tracers after chlorination by oral administration to rats. The tracer solutions have been tested according to a protocol derived from the OECD guideline for testing chemicals no. 423 "Acute oral toxicity - Acute toxic class method".

Batches of 3 female rats were formed and the animals received the test solution administered orally at a concentration of $10 \mathrm{mg} \cdot \mathrm{kg}^{-1}$ in a single dose on the first day. The animals had fasted overnight and access to food was restored 4 hours after treatment.

The dose tested belongs to group II of the packing groups described in "abstract ADR 2005-toxic substances," corresponding to moderately toxic substances (LD50 > 5-50 $\left.\mathrm{mg} \cdot \mathrm{kg}^{-1}\right)$. A control batch received the medium alone under the same conditions as the animals tested. All animals were observed for 14 days during which their weight, clinical signs and mortality were recorded daily. They were then sacrificed and a complete autopsy was carried out by macroscopic examination.

\section{Ecotoxicity tests}

The two standardized tests, described in Table 2, were selected to assess the ecotoxicity of the tracers' solutions after the degradation steps, i.e., the Daphnia magna immobilization test and the algal growth inhibition test. These two organisms are conventionally used to assess the effects of chemicals and effluents on the aquatic environment.

Both tests were carried out according to their respective standardized protocol. The organisms were exposed to a concentration range of the tracers' solution after the degradation steps and diluted with the respective test medium in order to determine $\mathrm{ECx}$ values. These values were derived from the concentration-response curves using a logistic Hill 
Table 2. Test conditions of the selected bioassays.

\begin{tabular}{|c|c|c|}
\hline Test & Daphnia magna immobilization test & Algal growth inhibition test \\
\hline Organism & Daphnia magna Straus 1820 & Pseudokirchneriella subcapitata \\
\hline Test method & NF EN ISO 6341 & NF EN ISO 8692 \\
\hline Endpoint & Mobility & Population growth \\
\hline Type of effect & Acute & Chronic \\
\hline Temperature & $20 \pm 2^{\circ} \mathrm{C}$ & $22 \pm 1^{\circ} \mathrm{C}$ \\
\hline Lighting & Darkness & $\begin{array}{l}\text { Continuous lighting (cool white light, within the range } \\
\qquad 5,760-7,010 \text { lux) }\end{array}$ \\
\hline Test duration & 48 hours & 72 hours \\
\hline Measurement & 24 and 48 hours & Cell counting at 24,48 and 72 hours \\
\hline $\begin{array}{l}\text { Control and } \\
\text { dilution medium }\end{array}$ & Synthetic medium (NF EN ISO 6341) & Synthetic medium (NF EN ISO 8692) \\
\hline Agitation & None & Continuous (125 rpm, orbital shaker). \\
\hline Test design & $\begin{array}{l}4 \text { replicates per test condition, } \\
4 \text { controls }\end{array}$ & $\begin{array}{c}3 \text { replicates per test condition, } \\
6 \text { controls } \\
1 \text { negative control per test condition }\end{array}$ \\
\hline Test vessel & Glass tubes filled with $10 \mathrm{~mL}$ of test solution & Erlenmeyer flasks filled with $100 \mathrm{~mL}$ of test solution \\
\hline $\begin{array}{l}\text { Number of } \\
\text { organisms }\end{array}$ & 5 per replicate & Initial density: 10000 cells $\cdot \mathrm{mL}^{-1}$ \\
\hline $\begin{array}{l}\text { Expression of } \\
\text { results }\end{array}$ & $\mathrm{EC}_{50} 48$ hours & $\mathrm{EC}_{10} ; \mathrm{EC}_{50} 72$ hours \\
\hline
\end{tabular}

model. The 95\% confidence intervals were estimated using a "bootstrap" simulation method. Calculations were performed with REGTOX software v.7.0.5.

The tracer solutions were filtered on $0.45-\mu \mathrm{m}$ filters prior to the preparation of the different concentrations for the algal growth inhibition test.

\section{TOXICITY AND ECOTOXICITY OF DEGRADED TRACERS}

\section{Nature of degradation byproducts}

The analytical results obtained by HPLC are presented in Fig. 3.
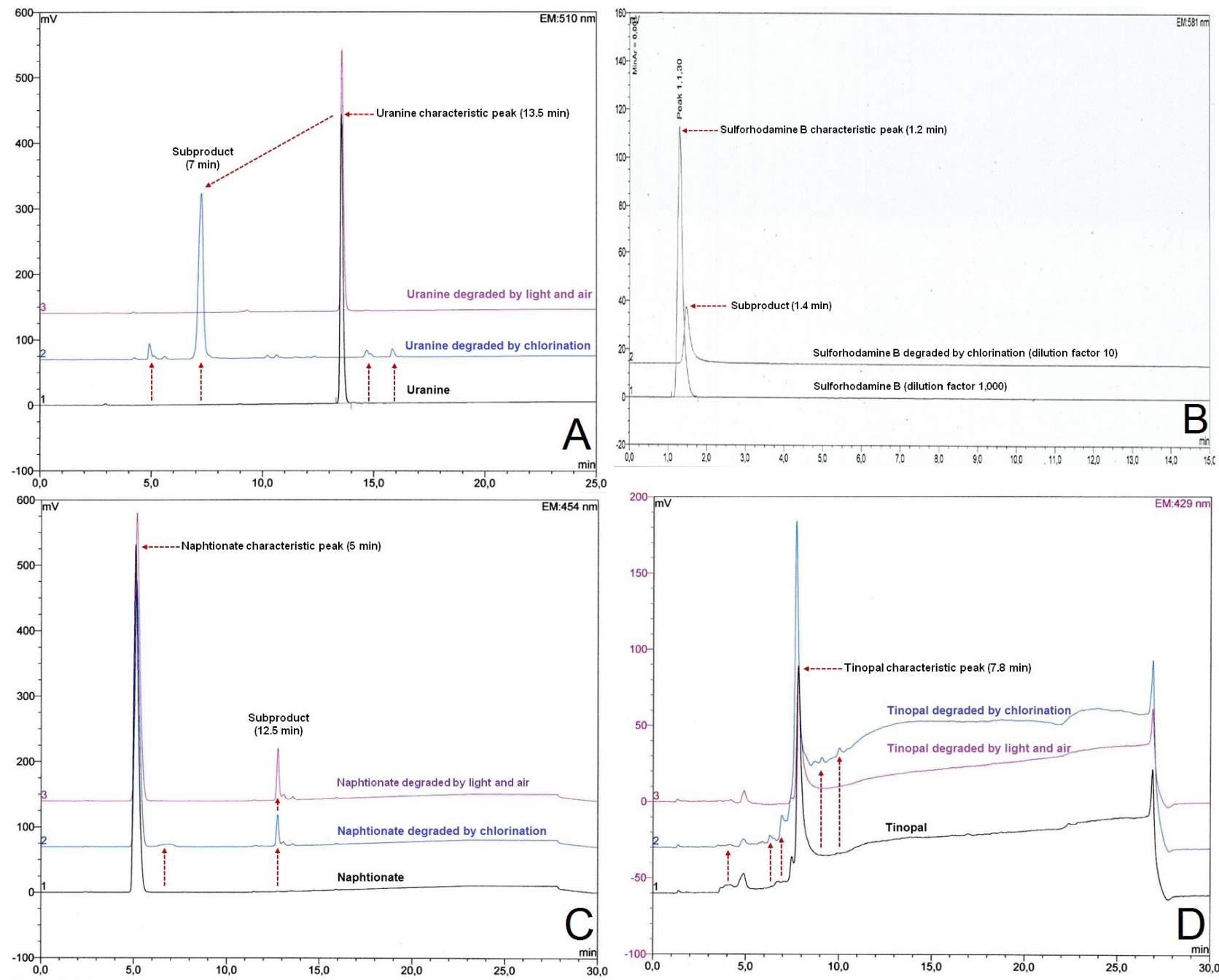

Fig. 3. Chromatograms of fluorescent tracers in fluorescence detection. A) Uranine; B) Sulforhodamine B; C) Naphtionate; D) Tinopal 8 . 


\section{Uranine}

After chlorination, we observed the complete disappearance of uranine, for which the retention time is 13.5 min. (Fig. 3A). In addition, we noted the appearance, in fluorescence detection, of several fluorescent compounds, the most significant of these having a retention time of about $7 \mathrm{~min}$. Unlike other minor compounds observed, however, this fluorescent compound was not detected by UV.

Four fractions of the eluent containing four major peaks detected by fluorescence were collected at around 5, 7, 15, and $16 \mathrm{~min}$. These fractions were analyzed by LC-MS in an attempt to identify the generated degradation compounds. However, regardless of the ionization mode, it was not possible to isolate their mass spectrum, probably because their concentrations were too low.

Another breakdown product, not fluorescent but detectable by UV at $210 \mathrm{~nm}$ and $220 \mathrm{~nm}$, was generated. Its HPLC retention time is 3.5 minutes. However, this compound is not present in sufficient quantities to allow for a possible identification by LC-MS.

Regarding light and air degradation (see also Fig. 3A), we observe a $10 \%$ decrease of the initial concentration, but no byproducts were noted either with UV or with fluorescence. That means the byproducts induced by the partial degradation of uranine are not fluorescent, and/or their concentration is too low to be detectable with UV.

\section{Sulforhodamine B}

After chlorination, we observed the complete disappearance of sulforhodamine $\mathrm{B}$, for which the retention time is $1.30 \mathrm{~min}$, (Fig. 3B). In addition, we noted the appearance in fluorescence detection of a single fluorescent compound at a retention time of $1.48 \mathrm{~min}$. Due to the significant dilution factor, the signal intensity of this new peak is about 500 times smaller than that of the initial sulforhodamine B peak.

The fraction corresponding to this peak was not collected for LC-MS analysis but a chromatogram in UV detection was performed. At a 210-nm wavelength, a main peak appears at $1.36 \mathrm{~min}$., for which a UV spectrum was plotted. The latter showed that the newly formed product has, instead of the 559-nm initial peak of sulforhodamine $\mathrm{B}$, a main absorption peak at $196 \mathrm{~nm}$ and a secondary peak at $297 \mathrm{~nm}$.

Note: for technical reasons, the degradation of this tracer by light and air action could not be carried out.

\section{Naphtionate}

During the chlorination of this tracer, with a retention time of $5 \mathrm{~min}$., there is a decrease of about $20 \%$ in its concentration. In addition, a degradation compound appeared at a retention time of $13 \mathrm{~min}$. This new compound is detectable by fluorescence (Fig. 3C) but hardly detectable in UV.

The fraction corresponding to this peak has been collected and analyzed by LC-MS in an attempt to identify the generated degradation compound. However, it was not possible to isolate the mass spectrum of this compound regardless of the ionization mode.
Regarding light and air degradation (see also Fig. 3C), we observe a $15 \%$ decrease of the initial concentration. A byproduct also appears that is easily detectable by fluorescence but very weakly by UV. As its retention time is similar to those induced by chlorination (13 min.), this byproduct seems to be the same.

\section{Tinopal®}

During the chlorination of this tracer, for which the retention time is $7.8 \mathrm{~min}$., we observed the appearance of a degradation compound at a slightly lower retention time ( $7.6 \mathrm{~min}$.) accompanied by other products between 6.5 and 10 minutes (Fig. 3D). These new compounds were also detected in UV.

The fraction of eluent containing the predominant peaks detected by UV (between 6.5 and 7.6 min., i.e., just before the Tinopal®) was collected. This fraction was analyzed by LC-MS in an attempt to identify the degradation compounds generated. No degradation products could be highlighted in ionization ESI+, but in ionization ESI-mode, an ion of molar mass 185 was detected (Fig. 4A). This molar mass corresponds to that of the benzaldehyde-2-sulpho-acid salt mentioned in previous studies as a degradation product of Tinopal $\mathbb{R}$ (Richner \& Kaschig, 1999). The compound causing this mass peak was isolated and fragmented in MS/ MS (Fig. 4B). This operation consists in subjecting the product to a bombardment of argon under pressure to break the molecules into sub-constituents of which the molar mass can then be calculated. The spectrum obtained confirmed this assumption: the presence of an ion of molar mass 80 (likely the ion $\mathrm{SO}_{3}{ }^{-}$), of an ion of molar mass 157 (likely the benzene sulfonic acid $\mathrm{C}_{6} \mathrm{H}_{5} \mathrm{SO}_{3}^{-}$).

Regarding light and air degradation (see also Fig. 3D), we observed a $30 \%$ decrease but no byproduct was detected by fluorescence or UV. That means the byproducts induced by partial degradation of Tinopal ${ }^{\circledR}$ are not fluorescent, and/or their concentration is too low to be detectable by UV.

\section{Toxicity of degradation byproducts}

The $\mathrm{pH}$ of the solutions of degraded tracers was in the appropriate range to expose rats to the Tinopal ${ }^{\circledR}$ and the naphtionate solutions but too low for the uranine solution (approximately 2.2). This solution has therefore been diluted to $1 / 3$ prior to administration; the final concentration of the tested degraded solutions is therefore $1 \mathrm{~g} \cdot \mathrm{L}^{-1}$ for Tinopal ${ }^{\circledR}$ and naphtionate and $0.33 \mathrm{~g} \cdot \mathrm{L}^{-1}$ for uranine. Given this low $\mathrm{pH}$, sustained monitoring has been performed, but the animals showed no clinical signs. This suggests either that the product was injected directly into the stomach (the low $\mathrm{pH}$ of which is compatible with that of the injected product), or that it was not overly harmful to the esophagus. In the absence of mortality and taking into account the absence of an inflammatory reaction observed during the autopsy on the esophagus, OECD Test Guideline 423 advocates in a $2^{\text {nd }}$ phase exposing a new batch of three rats to the same concentration in order to achieve a satisfactory statistical ability to determine whether or not the product is toxic at the concentration used. 


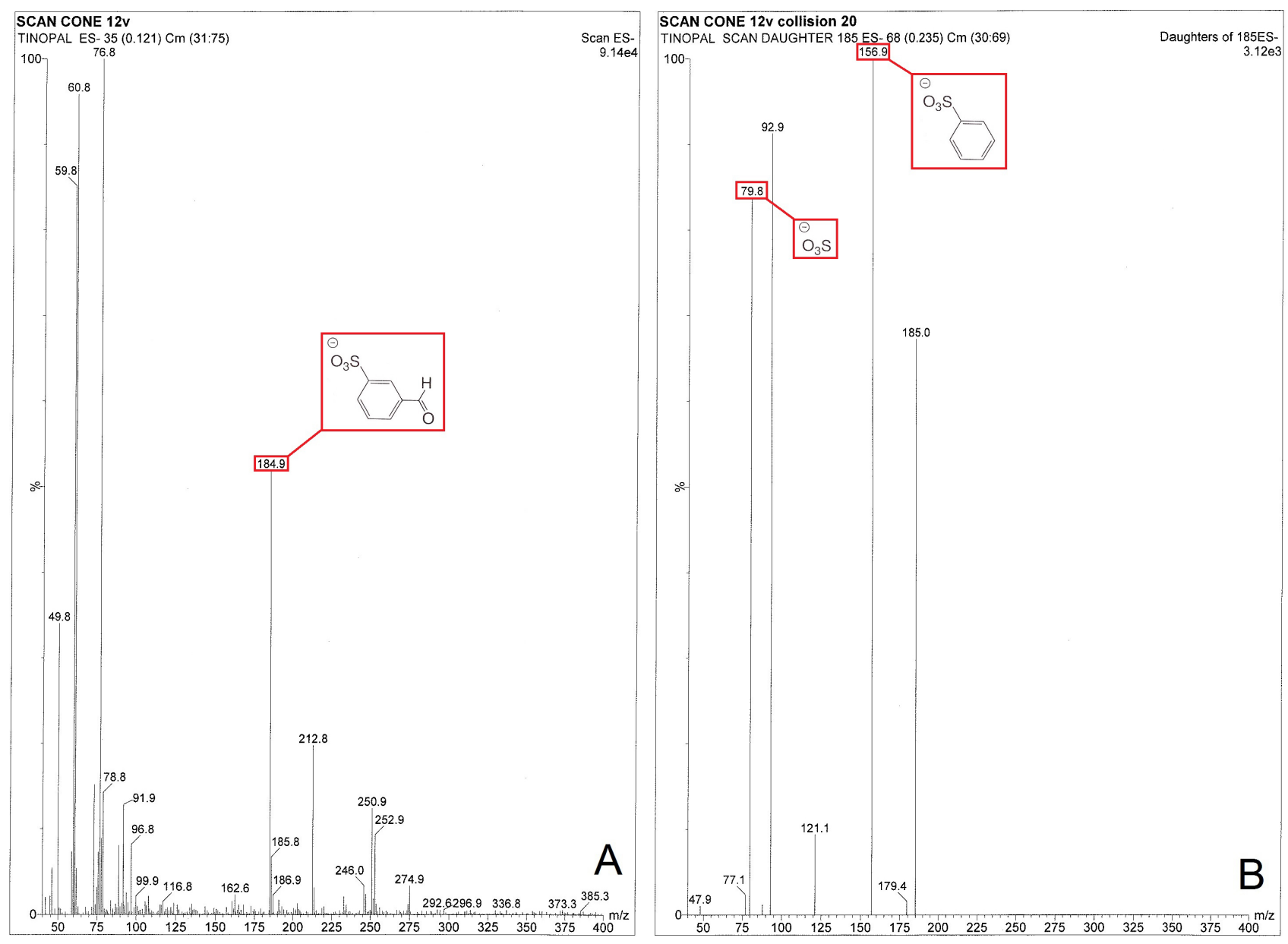

Fig. 4. Identification of a degradation product of Tinopal囚 by HPLC coupled to mass spectrometry. A) ESI- spectrum of degraded Tinopal 8 ;

B) Fragmentation of the " 185 " compound.

The $\mathrm{pH}$ measured in the degraded solutions of phase 2A was found to be identical to that of phase 1 .

None of the tracer solutions degraded by chlorine demonstrated toxicity in rats. No deaths or clinical effects were observed from a solution of 0.33 to $1 \mathrm{~g} \cdot \mathrm{L}^{-1}$, administered at a dose of $10 \mathrm{mg} \cdot \mathrm{kg}^{-1}$. During the autopsy, direct examination showed no macroscopic anomaly visible on the digestive tract. The average weight curves of animals in the various batches remained perfectly parallel to those of the control group for the two phases, leaving no evidence of the harmful effects of tracer ingestion (Fig. 5). This study thus confirms that the products tested are

\section{Phase 1}

Sex: Female

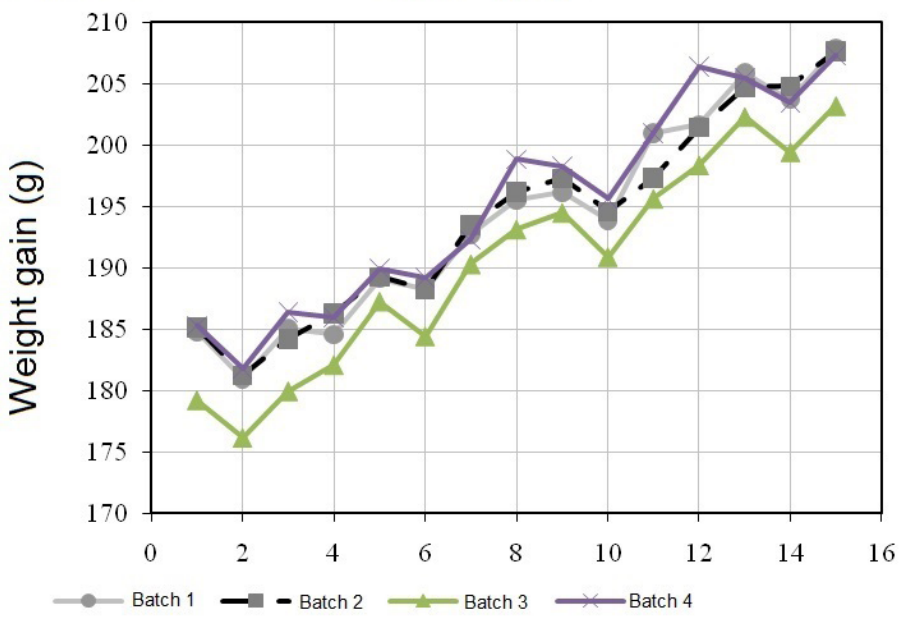

Fig. 5. Average weight gain of tested rats (from Gombert et al., 2010). not of Group I and II and that at concentrations by far exceeding environmental concentrations, they present no toxic risk to rats, and very likely neither to humans.

\section{Ecotoxicity of degradation products}

The results obtained for the three selected tracers are reported in Table 3.

Due to the lack of baseline data, as shown in Table 1, this study did not allow determination of the ecotoxicity of the degradation products alone. It therefore focused on the assessment of the ecotoxicity of the solutions of degraded tracers.

\section{Phase 2}

Sex: Female

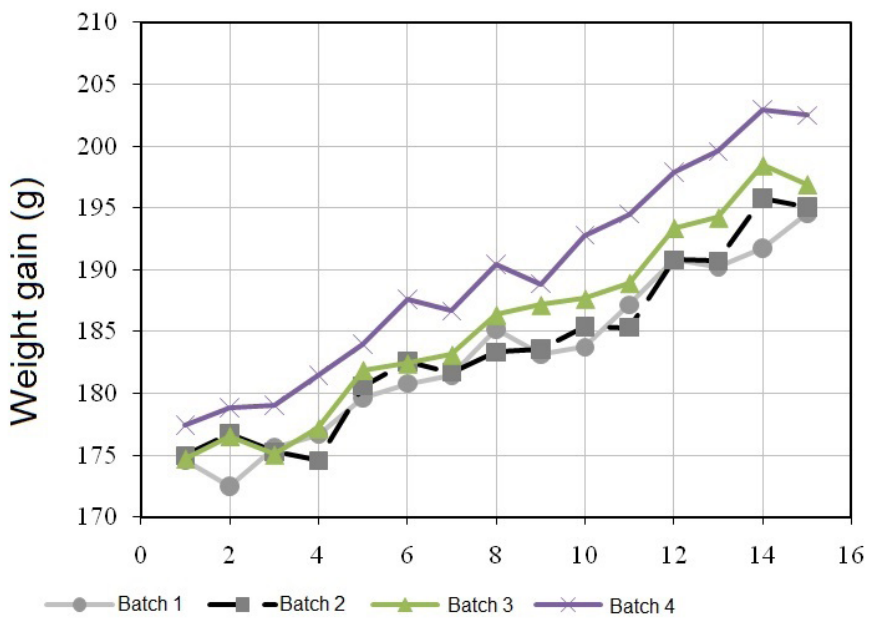


Table 3. Results of the ecotoxicity tests performed on solutions of degraded tracers. EC $x$ values are reported in \% solutions of degraded tracers with $95 \%$ confidence intervals.

\begin{tabular}{|c|c|c|}
\hline Tracer & Daphnia magna immobilization test & Algal growth inhibition test \\
\hline Uranine & $\begin{array}{l}\mathrm{EC}_{50}: \text { not determined ( } 40 \% \text { inhibition for } \\
\text { daphnids exposed to the undiluted solution) }\end{array}$ & $\begin{array}{l}\mathrm{EC}_{10}: 21.5 \%(14.6-29.5) \\
\mathrm{EC}_{50}: 77.8 \%(67.9-90.2)\end{array}$ \\
\hline Sodium naphtionate & $\mathrm{EC}_{50}: 56.4 \%(52.1-60.3)$ & $\begin{array}{l}\mathrm{EC}_{10}: 1.06 \%(0.87-1.26) \\
\mathrm{EC}_{50}: 4.04 \%(3.76-4.34)\end{array}$ \\
\hline Tinopal® & $\begin{array}{l}\mathrm{EC}_{50} \text { : not determined ( } 20 \% \text { inhibition for } \\
\text { daphnids exposed to the undiluted solution) }\end{array}$ & $\begin{array}{l}\mathrm{EC}_{10}: 70.9 \%(53.4-88.5) \\
\mathrm{EC}_{50}: \text { approx. } 100 \%\end{array}$ \\
\hline
\end{tabular}

These results showed a residual toxicity of the three tracers' solutions after the degradation steps, allowing classification: sodium naphtionate >> uranine > Tinopal ${ }^{\circledR}$ and a higher sensitivity of $P$. subcapitata compared with D. magna. For the most toxic one (i.e., sodium naphtionate), the EC50 $72 \mathrm{~h}$, expressed as initial nominal concentration of the tracer, was equal to $40 \mathrm{mg} \cdot \mathrm{L}^{-1}$. For the other two, the EC50s of the most sensitive species were higher than $750 \mathrm{mg} \cdot \mathrm{L}^{-1}$, reflecting the lack of short-term effects of the tested solutions for aquatic organisms.

\section{CONCLUSION}

In some specific contexts, as in chalky karst of Normandy, only a minority of tracer tests are positive. The injected tracers reach the water point and are introduced into the drinking water supply network. Under the impact of the water purification treatment (most often, disinfection by chlorination), they may degrade into byproducts. If swallowed, tracers and their degradation products could possibly be toxic to humans consuming the water.

A similar problem occurs for tracers that do not reach the targeted water point. They can be partially adsorbed in the aquifer but a significant part can be eliminated via karstic springs. In this second case, they join the surface waters where they may degrade due to sunlight and air interactions. These tracers can also degrade into byproducts, the composition and ecotoxicity of which are unknown for aquatic organisms.

Four of the most frequently used fluorescent tracers were studied here: uranine, sulforhodamine B, naphtionate and Tinopal ${ }^{\circledR}$. Previous studies have shown their toxicity and ecotoxicity to be globally negligible at the concentrations typically used in tracer tests, but the nature and toxicity of the degradation product(s) of these tracers are not mentioned.

We therefore reproduced in the laboratory an artificial degradation of these tracers by chlorination or by air and sunlight action. Several degradation byproducts identifiable by HPLC appeared in most cases. Because of their low concentration and the strong dilution inherent to the detection technique, it was unfortunately not possible to characterize these degradation byproducts, except for Tinopal ${ }^{\circledR}$. In this case, the product obtained by chlorination is identical to the one mentioned in the previous studies for degradation of this tracer in natural conditions, i.e., under the influence of sunlight and air. This could mean that, for the large organic molecules that fluorescent tracers are, the weakest chemical bonds are the same regardless of the intensity of the degradation.
For each of the above-mentioned degradation pathways, the toxicity of the byproducts has been tested, except for sulforhodamine B. The tested concentrations are on the order of $\mathrm{g} \cdot \mathrm{L}^{-1}$, that is to say medial between those used during injection and those observed in recovery points. No signs of acute toxicity have been demonstrated in rats after injection of solutions of degraded tracers. Regarding aquatic organisms, a residual ecotoxicity of these highly concentrated tracer solutions has been observed, mainly for sodium naphtionate.

In conclusion, these four fluorescent tracers have been tested at concentrations in excess of 50 times the maximum observed in recovery at drinking water capturing sites in the chalk karstic aquifer of Normandy. The tracers and their degradation byproducts appear to have no significant toxicological and ecotoxicological effects at the concentration commonly found in such context.

To obtain a complete view of the toxicity of the main hydrogeological tracers, work remains to be done for other fluorescent (amino G acid, eosin, etc.) or ionic (iodide, bromide, lithium, etc.) tracers.

\section{ACKNOWLEDGEMENTS}

We thank the DREAL (Regional Directorate of Environment, Planning and Housing) of Normandy (France) for financing this study on the degradation of four of the main fluorescent tracers used in the karstic chalk of Normandy. We are also grateful to our three anonymous reviewers for their constructive comments.

\section{REFERENCES}

Behrens H., Beims U., Dieter H., Dietze G., Eikmann T., Grummt T., Hanisch H., Henseling H., Käss W., Kerndorff H., Leibundgut C., Müller-Wegener U., Rönnefahrt I., Scharenberg B., Schleyer R., Schloz W. \& Tilkes F., 2001 - Toxicological and ecotoxicological assessment of water tracers. Hydrogeology Journal, 9: 321-325.

https://doi.org/10.1007/s100400100126

Benischke R., Goldscheider N. \& Smart C.C., 2007 Tracer techniques. In: Goldscheider N. \& Drew D. (Eds.) Methods in Karst Hydrogeology. Taylor \& Francis, London, p. 147-170.

Carré J., Joyeux M. \& Montiel A., 2007 - Risques sanitaires associés aux traceurs fluorescents utilisés en hydrologie. Environnement, Risques \& Santé, 6 (6): 443-452.

Crampon N, Roux J.C., Bracq P, 1993 - Hydrogéologie de la craie en France. Hydrogéologie, 2: 81-123.

ECHA, 2015 - Registered substances database. http:// echa.europa.eu/information-on-chemicals/registeredsubstances European Chemical Agency [accessed: February 12, 2015]. 
Field M.S., 2003 - Tracer-test planning using the Efficient Hydrologic Tracer-Test Design (EHTD) program. USEPA, National Center for Environmental Assessment, Washington, EPA/600/R-03/034.

Field M.S., Wilhelm R.G., Quinlan J.F. \& Thomas J.A., 1995 - An assessment of the potential adverse properties of fluorescent tracer dyes used for groundwater tracing. Environmental Monitoring and Assessment, $3 \mathbf{8}$ (1): 75-96.

https://doi.org/10.1007/BF00547128

Goldscheider N., Meiman J., Pronk M. \& Smart C., 2008 - Tracer tests in karst hydrogeology and speleology. International Journal of Speleology, 37: 27-40. https://doi.org/10.5038/1827-806X.37.1.3

Gombert P., 2007 - Proposition de protocole de traçage adapté au karst de la craie. European Journal of Water Quality, 38: 61-78. https://doi.org/10.1051/wqual/2007012

Gombert P., 2008 - Synthèse des traçages réalisés dans la craie karstique de Haute-Normandie et proposition de normalisation. Géologues, 159: 13-30.

Gombert P. \& Carré J., 2011 - Toxicité et écotoxicité des principaux traceurs fluorescents employés en hydrogéologie et de leurs produits de dégradation. Karstologia, 58: 54-64.

Käss W., 1998 - Tracing technique in geohydrology. Balkema, Rotterdam, 582 p.
Meus P., Schnegg P.A., Frippiat C. \& Monfort J., 2014 - Promises and limitations in the use of sulfonates colourless tracers in hydrogeology. Geologica Belgica, 17: $90-95$.

Molinari J. \& Rochat J., 1978 - Synthèse bibliographique sur la toxicité des substances fluorescentes utilisées en Hydrologie. International Journal of Speleology, 10 (3/4): 269-277.

https://doi.org/10.5038/1827-806X.10.3.4

Richner P. \& Kaschig J., 1999 - Degradable fluorescent whitening agents? Scientific contribution to overcome a prejudice. Ciba technical note, SETAC.

Rowinski P.M. \& Chrzanowsky M.M, 2011 - Influence of selected fluorescent dyes on small aquatic organisms. Acta Geophysica, 59: 91-109.

https://doi.org/10.2478/s11600-010-0024-7

Smart P.L., 1984 - A review of the toxicity of twelve fluorescent dyes used for water tracing. Bulletin of the National Speleological Society, 46: 21-33.

USEPA, 2015 - Ecotox Database. http://cfpub.epa.gov/ ecotox/quick_query.htm ECOTOX Knowledgebase [accessed: February 12, 2015].

Walthall W.K. \& Stark J.D., 1999 - The acute and chronic toxicity of two xanthene dyes, fluorescein sodium salt and phloxine $B$, to Daphnia pulex. Environmental pollution, 104 (2): 207-215.

https://doi.org/10.1016/S0269-7491(98)00189-4 